\title{
The temporal and social dimensions of river rehabilitation: towards a multi-dimensional research perspective
}

\author{
H. J. R. Lenders ${ }^{1 *}$ and L. Knippenberg ${ }^{2}$
}

With 2 figures in the text

\begin{abstract}
The three physical dimensions of river functioning (longitudinal, transversal and vertical) are scientifically acknowledged key features of river systems. In addition, this paper deals with two less tangible, but at least equally important dimensions: the temporal or fourth dimension, representing short- and long-term changes and dynamics, and the social or fifth dimension, including issues like cultural identity and various positions humans may hold towards nature. It is argued that these additional dimensions are essential for understanding rivers in their full context and to comprehend possibilities and constraints for river rehabilitation. Multi- or interdisciplinary research, explicitly including these additional dimensions, is needed to optimize river management in order to safeguard (culture-bound) ecological values and to guarantee public support. For this purpose, two conceptual models are presented that may serve as frameworks of interdisciplinary research programs.
\end{abstract}

Key words: temporal dimension, social dimension, research framework, nature-culture relationships, ecosocial complex.

\section{Introduction}

The scientific significance of the longitudinal, transversal and vertical dimensions of river functioning is presently - at least in theory - broadly recognized and accepted in river management. These three physical dimensions have been elaborated in terms of ecological concepts for river rehabilitation (VAN DER VELDE et al. 2003) such as: (1) the River Continuum Concept (VANNOTE et al. 1980) and the Serial Discontinuity Concept (WARD \& STANFORD 1995), (2) the Flood-Pulse Concept (Junk et al. 1989), and (3) the Flow-Pulse Concept (Tockner et al.

Authors' addresses: ${ }^{1}$ Department of Environmental Science, Institute for Wetland and Water Research, Radboud University Nijmegen, P.O. Box 9010, 6500 GL Nijmegen, The Netherlands. Participant of the Netherlands Centre for River Studies (NCR). ${ }^{2}$ Department of Social Environmental Science, Faculty of Social Sciences, Radboud University Nijmegen, P.O. Box 9104, 6500 HE Nijmegen, The Netherlands.

* Corresponding author: R.Lenders@science.ru.nl 
2000). Furthermore, a temporal or fourth dimension is acknowledged as an important feature of river functioning (BOON 1992, 1998; OJALA \& LOUEKARI 2002; Poudevigne et al. 2002; RiPL et al. 1994). This fourth dimension is usually elaborated in terms of physical river system processes, such as hydro- and morphodynamics, and accompanying phenomena such as succession and rejuvenation but also diurnal and seasonal time-cycles. Mostly, this elaboration is restricted to 'natural' processes; 'cultural' processes are often regarded beforehand as constraints to river functioning and are therefore seldom included in ideal-typical representations of rivers.

River scientists acknowledge that the wide array of river functioning concepts should not be regarded as competing paradigms, but rather as complementary conceptions of river systems that together may form a useful framework for river rehabilitation (TOWNSEND 1996; WARD et al. 2002). Geomorphologists, ecologists and hydrologists are therefore working together more and more, attempting to elaborate this multidimensional framework.

Within the context of a growing awareness and involvement of the public, the social or - following Boon $(1992,1998)$ - fifth dimension of river management is increasingly considered as an additional key factor for realistic and feasible perspectives of river rehabilitation. Questions regarding whether rehabilitation programs are broadly accepted among the public and how to interpret and organize actor-networks are of utmost importance to river management. Fortunately in the last decade, river-related research regarding ecological rehabilitation in the field of the social sciences may rejoice at an increasing interest (e.g. EDEN et al. 2000; Freeman \& Ray 2001; RhoAds et al. 1999; TAPSELl et al. 2001; Tunstall et al. 2000; WIERING \& DRIESSEN 2001). This social dimension should, however, not only imply an instrumental significance, nor should it solely concern guarantees for lowland rivers to fulfil functions other than strictly natural ones, such as flood prevention or navigation. It should also apply to other social and cultural functions, e.g. the conservation of cultural heritage and the ensuring of social well-being in terms of 'sense of belonging' and 'identity' (HENDrikx 1999) as well as the safeguarding of strongly threatened culture-bound nature. The social dimension also has a historical or temporal context; it results from centuries of interaction between human societies and river ecosystems. When elaborating on the tendency to develop a multidimensional framework for river rehabilitation, the full range of social functions (economic, cultural, psychological, etc.) should be taken into account. Only in this way the complexity of river systems can be fully understood, which is essential in recognizing impediments for ecological rehabilitation and in identifying culture-bound values, among which culture-bound nature. For this purpose, further co-operation between a wider range of scientific disciplines is needed also including archaeology, historical-geography, psychology, sociology and economics. To date, a multidimensional framework for interdisciplinary research is lacking. In this contribution, we make an attempt to extend and further clarify the significance of the fourth dimension and to exemplify the relevance of 
the social context of river rehabilitation (the fifth dimension). We do so by presenting two conceptual models that may function as starting points for multi- or interdisciplinary research that includes both the natural and the social sciences.

\section{A palaeoreference model for river rehabilitation: linearity vs. cyclicity?}

Rivers fulfil a pivotal function in the development and maintenance of human societies (see e.g. Smits et al. 2000b; Redman \& KinZIg 2003), but, in the course of time, societal activities have also moulded river systems to what they are today (Dynesius \& Nilsson 1994; Tockner \& Stanford 2002). Hence, there is an extensive interrelationship between a river's physical properties and the social structures and functioning of the human societies that it is interacting with. River rehabilitation programs cannot simply deny these historically rooted relationships and consider them as irrelevant. Awareness of the so-called 'longue durée' (BRAUDEL 1980; REDMAN \& KINZIG 2003), comprising large-scale and long-term social changes, may help us to understand present day river state and functioning and to recognize possibilities and constraints of rehabilitation. It may also help us to acknowledge that these interactions have not only led to an impairment of the ecological functioning of river systems, but that they have also yielded additional values, including a/o cultural-historical ones. Scientific reviews describing longterm historical society-river ecosystem relationships are scarce, especially those describing these relationships not only in terms of ecological decline but also in terms of cultural assets (ANdersen et al. 1996; Brown 2002; Large \& Petts 1996; Lenders 2003; OJala \& LoueKari 2002; Poudevigne et al. 2002; ShalLAT 2000). These publications indicate that the genesis of river landscapes is often, if not always, a spatio-temporally unique process with extensive human influences that reach back as far as the last Ice Age (see e.g. LendERs 2003; SvenNing 2002). Understanding this 'personal' history of a river is a prerequisite for river rehabilitation, both from the viewpoint of natural as well as cultural processes. It is essential to understand the historical reference of a particular river system and to include relevant endpoints in target images for river rehabilitation. Seemingly contradictory to their 'personal' histories, different rivers also show very similar patterns and processes concerning society-river ecosystem relationships, e.g. settlement location choice and agricultural land-use patterns. Apparently, there are common denominators in society-river ecosystem relationships of different rivers.

In general, human influence has unarguably led to the impairment of rivers concerning ecological functioning sensu stricto. The extinction by man of large river-related wild grazers (e.g. the Aurochs, Bos taurus primigenius; SvenNing 2002; VAN VUURE 2002) and creating possibilities for invasive species (BIJ DE VAATE 2003) are only a few of many examples. Human influence, however, has 
also led to a growing complexity due to an ever-increasing societal appeal for river system services, such as transport, waste water disposal and drinking water supply (SMits et al. 2000b). Present river systems can, therefore, not be merely considered as ecosystems in the traditional biological sense, but should be considered as ecosocial complexes (Haila 1999; Lenders 2003; OJala \& LoueKari 2002). These ecosocial complexes can only be fully understood when they are studied within an ecological context senso latu, including social, economic and culturalhistorical patterns and processes. An interesting example in this context is the study of TOL \& LANGEN (2000) that describes the vulnerability of river floods in the Netherlands during the last 1,000 years in terms of complex interactions of economics, institutions, politics and, but only to a limited extent, climate change. Understanding the historical social processes of river management appear to be at least equally important as understanding natural processes of large rivers.

Long-term descriptions of river systems evoke images of what may be called 'progressive linear' (i.e. non-cyclic) conceptions of time. This does not only apply to cultural aspects of river systems for which the linearity of time seems to be beyond discussion, following from, for example, the application of newly invented techniques (NAVEH 1998), but also to irreversible natural events, such as the palaeogeographical occurrences of avulsions (e.g. BerEndSEN \& Stouthamer 2001). A progressive linear understanding of time is predominantly found in scientific disciplines dealing with time spans that are usually beyond direct human perception. Such time scales are called 'mega- and macro-scales' (HaIla \& LEVINS 1992) and 'longue durée' or 'geographical time' (BRAUdel 1980). Disciplines dealing with such time scales are geology, archaeology, history, and evolutionary biology. Another example is the 'bottom up ecology' approach (SAGOFF 2003) which tries to identify the causes of particular phenomena in particular places at particular times without aiming to make them fit in universal scientific laws or concepts. The essence of the paradigms of these disciplines is that processes either do not obey strict scientific laws or, if they do, simultaneously occurring stochastic processes do not allow for well-predictable outcomes. As a consequence, processes are considered to be unique in time and irreversible, and nature is constantly changing into constitutions that never existed before ('nature in flux'; PImm 1991). The scientific approach of these disciplines is, therefore, predominantly retrospective and descriptive, but hardly ever predictive.Parallel to this progressive-linear understanding, a cyclic understanding of time is often applied, originating in particular from 'hard-core' natural sciences, such as chemistry and physics. The ecological variant is 'top-down ecology' (SAGOFF 2003). Large and by, these disciplines' starting points are that universal laws rule the physical world in a predictable way. In 'top down ecology', but also in conservation biology, these laws comprise cyclic processes or dynamic equilibria, such as diurnal and seasonal cyclicity. Outcomes of such processes are highly predictable, since cyclic processes or dynamic equilibria by definition return to their starting point or fluctuate around an attractor. This strong belief in cyclicity as the main guiding 


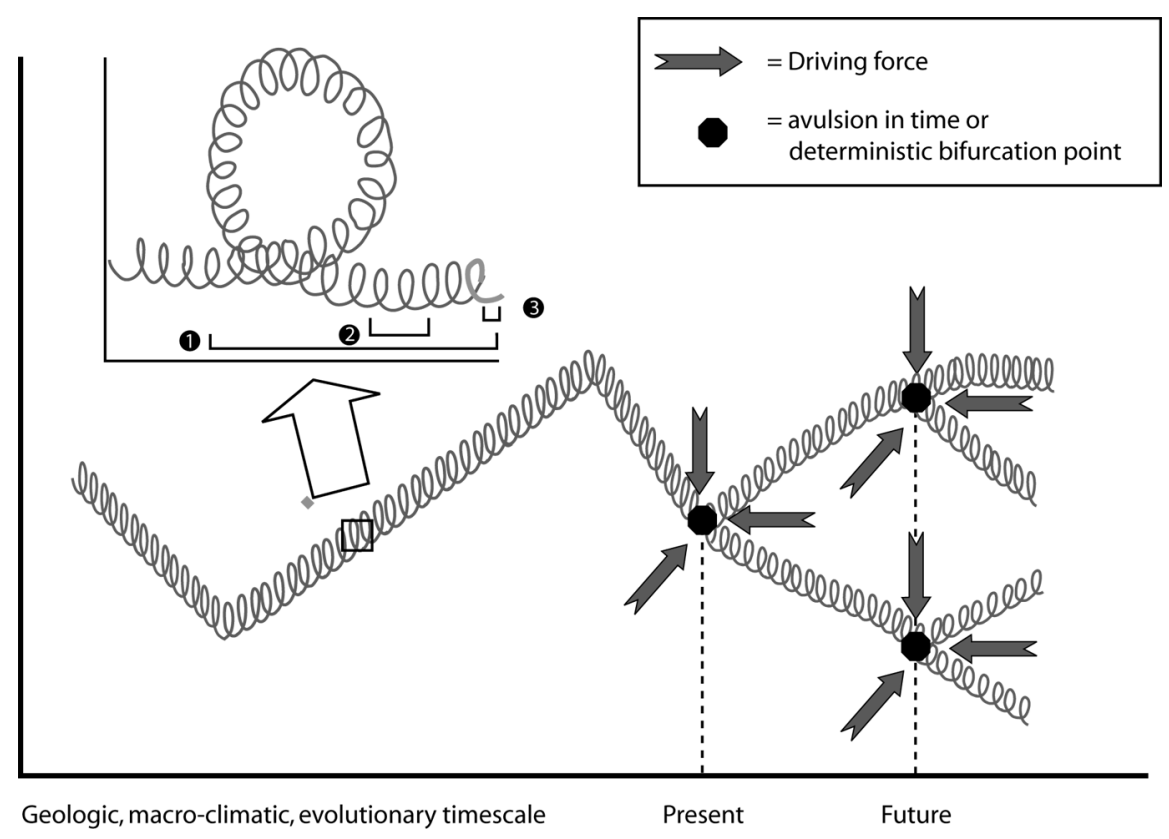

Fig. 1. Response of a (river) system (y-axis) to combined linear and cyclic temporal processes (x-axis). The low-scale cyclic processes comprise, for example, meso-climatic (1), seasonal (2) and diurnal (3) cycles; the high-scale linear processes comprise geologic, macro-climatic and evolutionary developments. The direction of the processes is determined by driving forces such as tectonics and human activities bringing the system to 'bifurcation points' or 'avulsions in time'.

principle can also be observed in many river rehabilitation approaches (e.g., BAPTIST et al. 2004; SMITs et al. 2000a; Vera 1997). In these approaches, 'cyclicity' is regarded as an indispensable management concept. By nature, this scientific approach has a strong predictive ambition, trying to explain and forecast future developments. One of the problems is that ecological research of this kind mostly concerns relatively short time spans (in the order of maximally a few decennia; Piмm 1991), as a result of which long-term, irreversible developments are often not recognized. This approach, however, is workable to explain and predict relatively short-term phenomena in nature.

Apparently, there seems to be a contradiction or at least a tension between the progressive-linear and the cyclic approaches. This paradox brings us to our first conceptual framework for interdisciplinary research in which we aim to make clear that an accurate temporal model can combine both approaches (Fig. 1). If only one of both approaches is applied, then it is not possible to accurately describe all of the processes and developments relevant to river systems functioning. The diagram 
represents the response of a fictitious river system to various factors changing in time. This response may relate to a wide variety of parameters, ranging from, for instance, primary production by the ecosystem, to the presence of a particular flora or fauna species and to the degree to which humans exploit the system agriculturally. Both cyclic and linear temporal developments are present. The cyclic scales comprise, e.g. meso-climatic cycles, seasonal cyclicity and diurnal cyclicity, while geological processes (tectonics), macro-climatic processes and evolutionary processes determine linear time-scales. For centuries, human activity has increasingly become a key factor in these linear processes. Occasionally, events both of human and non-human origin have exerted such an influence on the system that it transformed, gradually or by jumps, into an essentially different system as indicated by the bifurcations (Fig. 1). Tectonics, for example, may increase the slope of a river, which will lead to an increase of erosion and subsequently cause a decrease of primary production of the floodplain. The same effect, however, may occur as a result of human deforestation as it has occurred in the floodplains of many large rivers. Mostly, such driving forces initiate irreversible processes, which may be continuous processes ('forcing functions'), but also suddenly occurring disturbances ('major events'). The impact of such disturbances is determined by their severity, frequency, duration, spatial scale and points of interaction in space and time within the system (OJALA \& LOUEKARI 2002).

This temporal model of (river) system functioning may link up with a wide variety of scientific concepts and theories, such as 'punctuated equilibria' (ELDREDGE \& Gould 1977), 'deterministic complexity' (Manson 2001; NAVEH 1998) and 'panarchy' (including self control; GundERson \& Holling 2002). The model is also in line with RIPL et al.'s (1994) concept of irreversibly developing river systems, although far less deterministic and fatalistic since our model keeps open the opportunity to actively correct the course developments will take. Testing and applying such concepts as frameworks for understanding river functioning may be a promising challenge for multidisciplinary teams of river scientists and yield dynamic references based on the rivers' own histories (dynamic palaeoreferences).

\section{The role of humans in river systems: the fifth dimension}

The era of river rehabilitation, especially in Europe and North-America, marks a turning point in what is considered the undesired influence of human society on the natural environment. Regarding many river systems in western societies, three trends may be identified that describe the underlying processes that have led to this undesired development. These processes, individually or together, have inevitably led to the alienation of society from nature in general and from the river in particular (LENDERS 2003). In order to be aware of these developments and to understand the constraints they put on rehabilitation projects, three trends can be distinguished. 
1. From 'pristine' to rural to urban. Many river systems have changed from a 'pristine' landscape through an agricultural to an industrial and urban landscape. Presently, industry, housing and accompanying infrastructure increasingly determine the face of river landscapes (KUIPER 1998). Traditional agricultural land use forms have disappeared or transformed into purely cultural agroindustrial landscapes (sensu NAVEH 1998) resulting in 'mental urbanization' of farmers expressing that farmers detach from the rural landscape they live in and produce agricultural goods using industrial production methods. Ecological rehabilitation can be considered as a contra-movement to this ongoing dominance of humans over nature. It does not, however, undo alienation from nature since a strict division of the physical world is often still advocated, separating it into cultural and 'pristine' natural sub-worlds.

2. From local to global. The scale on which societal actions occur increases over time: from individual farming practices in prehistory over communitybased river dike construction in the Middle-Ages to national river regulation measures in the $18^{\text {th }}$ and $19^{\text {th }}$ century to, finally, the international abatement of pollution and flood risk reduction in the $20^{\text {th }}$ and $21^{\text {st }}$ century. This trend offers the opportunity to approach and tackle problems from a river basin perspective and appears to be useful from strict ecological and hydrological points of view (river catchment approach), but it also implies the risk of generic and high-level scale ways of action thereby overlooking local differences and ignoring community-based initiatives (RHOADs et al. 1999).

3. From involution to substitution. In the course of time, technocratic designing started dominating over organic origination (involution) of river landscapes (cf. Hamilton 2002). The landscape no longer developed gradually on the basis of natural characteristics under cultural influence, but was planned more and more top-down on the basis of technological possibilities to curb 'unfavourable' natural circumstances. This change to planned design went hand in hand with the nearly overnight substitution of large parts of the river landscape by 'pure' cultural forms of land use. Different forms of land use, presently including 'ecological rehabilitation' (LENDERs 2003; RENES 2003), follow each other in a high pace without taking into account the often age-old characteristics of their predecessors.

Presently, social-cultural and socio-economic values are increasingly taken into account due to a growing public awareness and participation. The public has become more emancipated and is less likely to uncritically accept directives from governmental authorities. Besides the acknowledgement of the intrinsic value of nature (VAN DEN BORN et al. 2001), the general public holds certain social-cultural values that result from an (implicit) linkage of tangible, especially cultural-historical landscape features, inherited from one's ancestors, and intangible values such as 'identity' and 'well-being' (HENDrikx 1999; Schama 1995) as opposed to alienation from the landscape. 


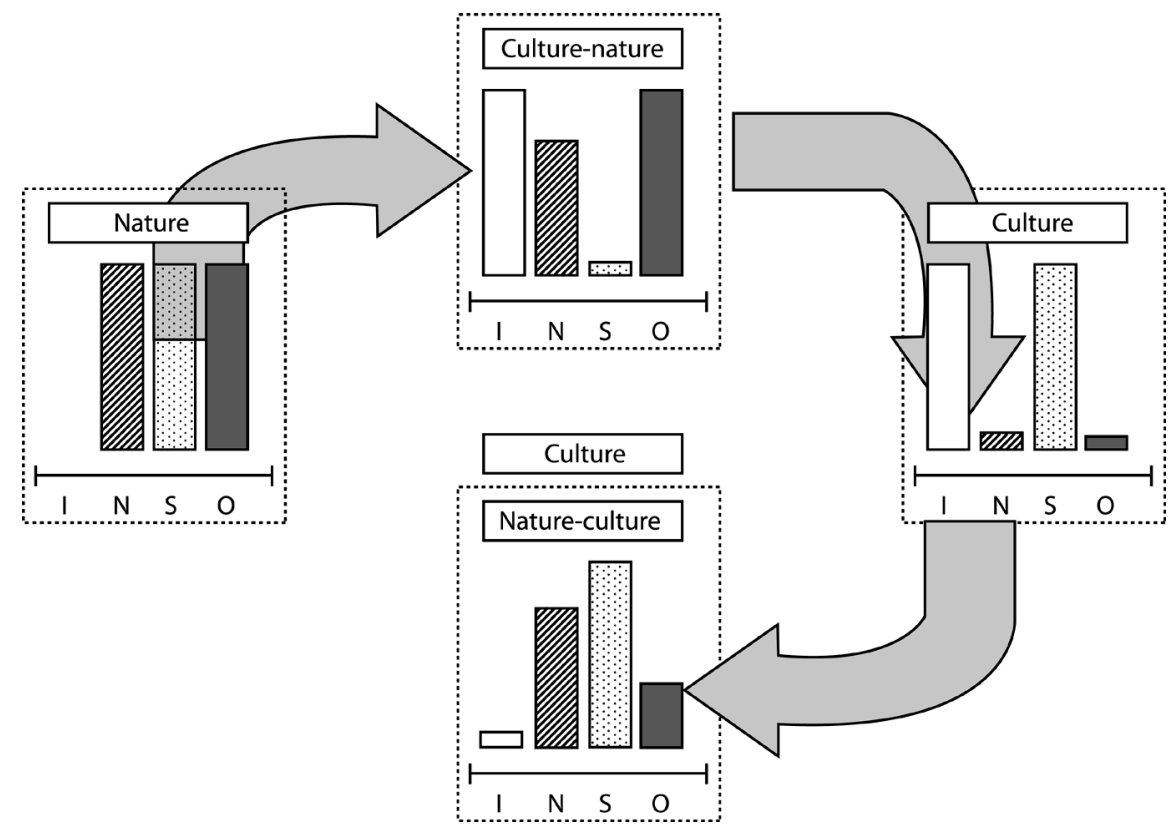

Fig. 2. The transformation process of four archetypical entities of (combinations of) 'nature' and 'culture'; I = degree of man-inclusiveness of the archetype; $\mathrm{N}=$ degree of naturalness of the archetype; $\mathrm{S}=$ degree of separation of man and nature within the archetype; $\mathrm{O}=$ degree of organic origination of the archetype.

Furthermore, the public (as well as authorities) may feel a friction between images of 'pure natural' river systems and the socio-economic functions that the river landscape has to fulfil to meet the needs of society. Contrarily, especially at the regional level, there seems to be a growing awareness that river rehabilitation may also yield local economic benefits (e.g., Amigues et al. 2002; ConNely et al. 2002; KLiNe et al. 2000; Kosz 1996; Loomis et al. 2000). Thus, from both a psychological/sociological viewpoint (socio-cultural) as well as from a more utilitarian point of view (socio-economic), it appears that social and societal demands and preferences play an increasing role in (re-)designing, conserving and managing the river landscape.

On the basis of these socio-temporal developments in river systems, four archetypes regarding nature-society relationships in river systems can be distinguished (Fig. 2). Together, these archetypes may function as the second interdisciplinary framework for river functioning and rehabilitation research, especially with regard to the identification of historical references and the formulation of feasible and societally desired endpoints. The archetypes can be characterized by four criteria: 
(1) the degree to which humans are an intrinsic part of the system (I), (2) the degree to which the system can be regarded as 'natural' $(\mathrm{N}),(3)$ the degree to which nature and culture are regarded as separated entities (S), and (4) the degree to which the system may be regarded as organically originated $(\mathrm{O})$ as opposed to being planned top-down.

The first archetype concerns 'pure' nature. Using 'pure' nature as a reference for river rehabilitation denies social and cultural values of the eco-social-complex and presupposes that humans have only a negative impact on the environment. Furthermore, these 'pure wilderness' systems were probably never a reality for many lowland river systems - including, for instance, the Rhine-Meuse delta since at least the last glacial. Also for other ecosystems - among which the showpiece of 'undisturbed' ecosystems, the Amazon rain forest - the presumed 'pristine' character has recently been brought under discussion (CLEARY 2001). The second archetype concerns 'culture-nature' river systems (cf. EDEN et al. 2000): they are fully man-inclusive and, as a consequence, show a low level of separation of nature and culture whereas the levels of naturalness and organic origination are still relatively high. They result from the co-evolution of human society and nature, in which nature sets boundary conditions and humans comply with the physiognomy of the landscape they encounter. In the course of time, this archetype has degenerated in most river systems into the third, almost fully cultural archetype. Society tries to manage nature at will and nature is submitted to substitution instead of involution. Alienation from nature has reached its maximum, and it is this phase in which most lowland rivers in developed countries are today. This phase is also the breeding ground to acknowledge this is not sustainable river management. The fourth archetype is what most river rehabilitation projects presently aim at. This archetype consists of two subtypes of land use: a fully cultural subtype (e.g. the former flood basin disconnected from the river by embankments and intensive agro-industrial use) and the 'nature-culture' subtype, being a presentday societal expression of how a more natural river system should look like. This archetypical subtype is characterized by a (very) low level of man-inclusiveness and consequently a high level of separation of nature and culture, and a relatively high level of naturalness. The 'pure' nature archetype is often used as a reference for this subtype. In our opinion, however, this is unjust because of the denial of social and cultural values and of the positive role humans can play within the river system. Furthermore, this subtype is characterized by a relative low level of organic origination, since this subsystem is clearly planned top-down and restricted by constraints put upon it by the cultural subsystem (e.g. restrictions resulting from maintaining the navigability of the river and realising flood risk reduction levels).

The ways in which the four criteria used to characterize the archetypes relate to one another raise interesting questions for a multidisciplinary or interdisciplinary research program of both the natural and the social sciences. It will certainly help to clarify the structure and functioning of the ecosocial complexes of river landscapes. In our opinion, the 'culture-nature' archetype in particular deserves further 
research as to how it can serve as a useful reference for river rehabilitation, since this type offers opportunities that do justice to natural as well as social and cultural values.

\section{Concluding remarks}

River research and rehabilitation are in desperate need of multi- or interdisciplinary research programs to address management issues of river systems. Such programs should obviously include the three physical dimensions of river systems, as well as the temporal fourth dimension. Further research, however, should also comprise the social sciences clarifying the fifth dimension of river functioning. This dimension comprises both social-cultural and socio-economic elements. Joined research by social and natural scientist will beyond doubt lead to a better understanding of the ecosocial complexes that rivers are. By presenting (1) contrasting conceptions of time (linear vs cyclic) and (2) relationships between the natural and social domain, we introduced two frameworks for wider interdisciplinary research. The development of nature-society relationships from 'pure nature' to 'culture-nature' and 'pure culture' to 'nature-culture' clearly represents a progressive-linear development; on the other hand, the inclination towards 'nature-culture' implies a partial 'return' to the 'pristine' states of the river landscape and may be regarded as a cyclic movement. Further elaboration of the relationship between both conceptual models is a challenge that lies before us.

\section{Acknowledgments}

The authors wish to thank dr. MariëLle van der Zouwen and dr. Richard Sparks for their useful comments on an earlier version of this paper. Furthermore, we thank the editors dr. Tom Buisse, dr. Hans Middelkoop and dr. Rob Leuven for the fruitful discussions which have for sure contributed to further improvement of the manuscript.

\section{References}

Amigues, J.P., Boulatoff, C., Desaigues, B., Gauthier, C. \& Keith, J.E. (2002): The benefits and costs of riparian analysis habitat preservation: a willingness to accept/ willingness to pay contingent valuation approach. - Ecol. Economics 43: 17-31.

Andersen, O., Crow, T.R., Lietz, S.M. \& Stearns, F. (1996): Transformation of a landscape in the upper mid-west, USA: The history of the lower St. Croix river valley, 1830 to present. - Landscape and Urban Planning 15: 247-267.

Baptist, M.J., Penning, W.E., Duel, H., Smits, A.J.M., Geerling, G.W., Van der Lee, G.E.M. \& VAN AlPhEN, J.S.L. (2004): Assessments of the effects of cyclic floodplain rejuvenation on flood levels and biodiversity along the Rhine River. - River Research and Applications 20: 285-297.

Berendsen, H.J.A. \& Stouthamer, E. (2000): Late Weichselian and Holocene palaeogeography of the Rhine-Meuse delta, the Netherlands. - Palaeogeogr., Palaeoclimatol., Palaeoecol. 161: 311-335. 
BiJ DE VAATE, A. (2003): Degradation and recovery of the freshwater fauna in the lower sections of the rivers Rhine and Meuse. - PhD-thesis, Univ. of Wageningen.

Boon, P.J. (1992): Essential elements in the case for river restoration. - In: P.J. Boon, P. Calow \& G.E. Petts (eds.): River Conservation and Management. J. Wiley, Chichester.

- (1998): River restoration in five dimensions. - Aquatic Conservation: Marine and Freshwater Ecosystems 8: 257-264.

Braudel, F. (1980): On History. - Weidenfeld \& Nicolson, London.

Brown, A.G. (2002): Learning from the past: palaeohydrology and palaeoecology. Freshwater Biol. 47: 817-829.

Cleary, D. (2001): Towards an environmental history of the Amazon. From prehistory to the nineteenth century. - Latin Amer. Res. Rev. 36: 64-96.

Connely, N.A., Knuth, B.A. \& Kay, D.L. (2002): Public support for ecosystem restoration in the Hudson River Valley, USA. - Environm. Management 29: 467-476.

Dynesius, M. \& Nilsson, C. (1994): Fragmentation and flow regulation of river systems in the northern third of the world. - Science 266: 753-762.

Eden, S., Tunstall, S.M. \& TAPsell, S.M. (2000): Translating nature: river restoration as nature-culture. - Environment and Planning D: Society and Space 18: 257-273.

EldRedge, N. \& Gould, S.J. (1977): Punctuated equilibria: an alternative to phyletic gradualism. - In: T.J. ScHOPf (ed.): Models in palaeobiology. Freeman, Cooper \& Co., San Francisco.

FreEman, R.E. \& Ray, R.O. (2001): Landscape ecology practice by small scale river conservation groups. - Landscape and Urban Planning 56: 171-184.

Gunderson, L.H. \& Holling, C.S. (2002): Panarchy. Understanding transformations in human and natural systems. - Island Press, Washington.

HaIla, Y. (1999): Biodiversity and the divide between culture and nature. - Biodiversity and Conservation 8: 165-181.

Haila, Y. \& Levins, R. (1992): Humanity and nature: ecology, science and society. Pluto Press, London.

Hamilton, C. (2002): Dualism and sustainability. - Ecol. Economics 42: 89-99.

Hendrikx, J.A. (1999): Cultuurhistorie van stad en land. Waardering en behoud. - Matrijs, Utrecht [in Dutch]

Junk, W.J., Bailey, P.B. \& Sparks, R.E. (1989): The flood pulse concept in river floodplain systems. - In: D.P. DoDGE (ed.): Proceedings of the International Large River Symposium (LARS). Canad. Special Publ. Fisheries and Aquat. Sci. 106: 110-127.

Kline, J.D., Alig, R.J. \& Johnson, R.L. (2000): Forest owner incentives to protect riparian habitat. - Ecol. Economics 33: 29-43.

Kosz, M. (1996): Valuing riverside wetlands: the case of the "Donau-Auen" national park. - Ecol. Economics 16: 109-127.

KuIPER, J. (1998): Landscape quality based upon diversity, coherence and continuity. Landscape planning at different planning-levels in the River area of The Netherlands. - Landscape and Urban Planning 43: 91-104.

Large, A.R.G. \& PetTs, G.E. (1996): Historical channel-floodplain dynamics along the River Trent. - Appl. Geogr. 16: 191-209.

LENDERS, H.J.R. (2003): Environmental rehabilitation of the river landscape in the Netherlands. A blend of five dimensions. - PhD-Thesis, Univ. of Nijmegen. 
Loomis, J., Kent, P., Strange, L., Fausch, K. \& Covich, A. (2000): Measuring the total economic value of restoring ecosystem services in an impaired river basin: result from a contingent valuation survey. - Ecol. Economics 33: 103-117.

Manson, S.M. (2001): Simplifying complexity: a review of complexity theory. - Geoforum 32: 405-414.

NAveH, Z. (1998): Ecological and cultural landscape restoration and the cultural evolution towards a post-industrial symbiosis between human society and nature. - Restoration Ecology 6: 135-143.

OJala, E. \& LoueKari, S. (2002): The merging of human activity and natural change: temporal and spatial scales of ecological change in the Kokemäenjoki river delta, SW Finland. - Landscape and Urban Planning 61: 83-98.

Pimm, S.L. (1991): The balance of nature? Ecological issues in the conservation of species and communities. - The Univ. of Chicago Press, Chicago.

Poudevigne, I., Alard, D., Leuven, R.S.E.W. \& Nienhuis, P.H. (2002): A system approach to river restoration: a case study in the lower Seine valley, France. - River Research and Applications 18: 239-247.

Redman, C.L. \& Kinzig, A.P. (2003): Resilience of past landscapes: resilience theory, society and the longue durée. - Conservation Ecology 7 (1): 14. [online] URL: http://www.consecol.org/vol7/iss1/art14.

RENES, J. (2003): Nieuwe natuur in een oud landschap; cultuurhistorie en natuurontwikkeling in het rivierengebied. - De Levende Natuur 104. [in Dutch]

Rhoads, B.L., Wilson, D., Urban, M. \& Herricks, E.E. (1999): Interaction between scientists and nonscientists in community-based watershed management: emerge of the concept of stream naturalization. - Environm. Management 24: 297-308.

Ripl, W., Pokorny, J., Eiseltova, M. \& Ridgill, S. (1994): A holistic approach to the structure and function of wetlands and their degradation. - IWRB publ. 32: 16-35.

SAGoff, M. (2003): The plaza and the pendulum: two concepts of ecological science. Biology and Philosophy 18: 529-552.

Schama, S. (1995): Landscape and memory. - Harper Collins, London.

Shallat, T. (2000): Ecology in policymaking: Water and the restoration of America's Snake River Plain. - Water Policy 2: 327-341.

Smits, A.J.M., Havinga, H. \& Marteijn, E.C.L. (2000a): New concepts in river and water management in the Rhine river basin: how to live with the unexpected? - In: A.J.M. Smits, P.H. Nienhuis \& R.S.E.W. Leuven (eds.): New approaches to river management. Backhuys Publ., Leiden.

Smits, A.J.M., Nienhuis, P.H. \& Leuven, R.S.E.W. (eds.) (2000b): New approaches to river management. - Backhuys Publ., Leiden.

SvENNING, J.-C. (2002): A review of natural vegetation openness in north-western Europe. - Biol. Conservation 104: 133-148.

Tapsell, S., Tunstall, S., House, M., Whomsley, J. \& Macnaghten, P. (2001): Growing up with rivers? Rivers in London children's world. - Area 33: 177-189.

Tockner, K., Malard, F. \& Ward, J.V. (2000): An extension of the flood pulse concept. - Hydrological Processes 14: 2861-2883.

Tockner, K. \& Stanford, J.A. (2002): Riverine flood plains: present state and future trends. - Environm. Conservation 29: 308-330. 
Tol, R.S.J. \& LAngen, A. (2000): A concise history of Dutch river floods. - Climatic Change 46: 357-369.

TownSEND, C.R. (1996): Concepts in river ecology: pattern and process in the catchment hierarchy. - Arch. Hydrobiol. Suppl. 113 (Large Rivers 10): 3-21.

Tunstall, S.M., Penning-Rowsell, E.C., Tapsell, S.M. \& Eden, S.E. (2000): River restoration: public attitudes and expectations. - J. CIWEM 14: 363-370.

Van den Born, R.J.G., Lenders, H.J.R., De Groot, W.T. \& Huijsman, E. (2001): The new biophilia: an exploration of visions of nature in Western countries. - Environm. Conservation 28: 65-75.

Van der Velde, G., Leuven, R.S.E.W. \& Nagelkerken, I. (2003): Types of riverine ecosystems. - In: J.C.I. Dooge (ed.): Water Sciences, Engineering and Technology. Fresh surface water. Encyclopedia of life support systems (EOLSS). UNESCO, EOLSS Publ. Co. Ltd., France.

Vannote, R.L., Minshall, G.W., Cummins, K.W., Sedell, J.R. \& Cushing, C.E. (1980): The River Continuum Concept. - Canad. J. Fisheries and Aquat. Sci. 37: $130-137$.

VAN VuURe, C. (2002): History, morphology and ecology of the Aurochs (Bos taurus primigenius). - Lutra 45: 3-17.

Vera, F.W.M. (1997): Metaforen voor de wildernis. Eik, Hazelaar, Rund, Paard. - PhDThesis, Ministerie van LNV, Den Haag. [in Dutch]

Ward, J.V., Robinson, C.T. \& Tockner, K. (2002): Applicability of ecological theory to riverine ecosystems. - Verh. Internat. Verein. Limnol. 28: 443-450.

WARD, J.V. \& STANFORD, J.A. (1995): The serial discontinuity concept: extending the model to floodplain rivers. - Regulated Rivers: Research and Management 10: 159168.

Wiering, M.A. \& Driessen, P.P.J. (2001): Beyond the art of diking: interactive policy on river management in The Netherlands. - Water Policy 3: 283-296.

Received: 28 November 2003; revised: 20 September 2004; accepted: 20 September 2004. 
